\title{
Alterações em Argissolo sob vinhedo no sul do Brasil
}

\author{
Changes in typical Acrisol under vineyard in southern Brazill \\ Cambios en el Acrisol en viñedo en el sur de Brasil
}

Recebido: 01/02/2021 | Revisado: 06/02/2021 | Aceito: 06/02/2021 | Publicado: 14/02/2021

Estéfane Chaves

ORCID: https://orcid.org/0000-0001-9102-1429 Universidade Federal do Rio Grande do Sul, Brasil E-mail: ecagronomia@gmail.com

Caroline Valverde dos Santos

ORCID: https://orcid.org/0000-0001-9432-4804 Universidade Estadual do Sudoeste da Bahia, Brasil E-mail: caroline.valverde@uesb.edu.br

Vanessa Thoma Bertolazi

ORCID: https://orcid.org/0000-0003-3604-5545 Universidade Federal do Rio Grande do Sul, Brasil E-mail: vanessabertolazi@yahoo.com.br

Alberto Vasconcellos Inda Junior

ORCID: https://orcid.org/0000-0001-5252-0313

Universidade Federal do Rio Grande do Sul E-mail: alberto.inda@ufrgs.br

Renato Levien

ORCID: https://orcid.org/0000-0002-3274-0228

Universidade Federal do Rio Grande do Sul, Brasil E-mail: renatole@ufrgs.br

\begin{abstract}
Resumo
Este trabalho teve por objetivo avaliar a evolução mineralógica e alterações provocadas no solo e na fração argila após 15 anos de cultivo com videiras. Foi realizada amostragem nos horizontes A2 e Bt1 (até $60 \mathrm{~cm}$ de profundidade) de um Argissolo Vermelho Distrófico típico, para a realização de analises físicas, químicas e mineralógicas. As áreas deste estudo são compostas por um vinhedo comercial manejado por 4, 9 e 16 anos com a cultivar Pinot noir (Vitis Vinifera), enxertada em 1103 Paulsen, e uma área sob campo nativo, localizada próximo ao vinhedo para ser utilizada com referência. Verificou-se uma alteração na fertilidade do solo, em todas as profundidades amostradas e a partir de 4 anos de plantio. $\mathrm{O}$ argilomineral predominante no solo foi a caulinita $(\mathrm{Ct})$, contendo ainda, mica $(\mathrm{Mc})$, Feldspato potássico $(\mathrm{Ft})$ e quartzo (Qz). De modo geral, o vinhedo apresentou alterações nos atributos químicos do solo ao longo dos anos, com maior destaque nas áreas manejadas por 9 e 16 anos, onde o solo sofreu maior aporte de adubos químicos e corretivos agrícolas. Os resultados obtidos demonstraram que no vinhedo cultivado ha 4 anos houve indícios de Ilitização, resultante da adubação potássica intensa nos primeiros anos de cultivo, que promoveu a neoformação de Ilitas e argilominerais interestratificados.
\end{abstract}

Palavras-chave: Videiras; Solos; Mineralogia.

\begin{abstract}
This work aimed to evaluate the mineralogical evolution and alterations caused in the soil and clay fraction after 15 years of cultivation with vines. Sampling was carried out on horizons A2 and Bt1 (up to $60 \mathrm{~cm}$ deep) of an Acrisol (WRB/FAO), for physical, chemical and mineralogical analyzes. The areas of this study are composed of a commercial vineyard managed for 4, 9 and 16 years with the cultivar Pinot noir (Vitis Vinifera), grafted in 1103 Paulsen, and an area under native field, located close to the vineyard to be used with reference. There was a change in soil fertility, at all depths sampled and after 4 years of planting. The predominant clay in the soil was kaolinite (Ct), containing mica $(\mathrm{Mc})$, potassium feldspar $(\mathrm{Ft})$ and quartz $(\mathrm{Qz})$. In general, the vineyard showed changes in the chemical attributes of the soil over the years, with greater emphasis on the areas managed for 9 and 16 years, where the soil suffered a greater supply of fertilizers and agricultural corrective materials. The results obtained showed that in the vineyard cultivated 4 years ago there was evidence of Ilitization, resulting from intense potassium fertilization in the first years of cultivation, which promoted the new formation of Ilitas and inter-ratified clay minerals.
\end{abstract}

Keywords: Vines; Soils; Mineralogy.

\section{Resumen}

Este trabajo tuvo como objetivo evaluar la evolución mineralógica y las alteraciones provocadas en la fracción suelo y arcilla después de 15 años de cultivo con viña. El muestreo se realizó en los horizontes A2 y Bt1 (hasta $60 \mathrm{~cm}$ de 
profundidad) de un Acrisol (WRB/FAO), para análisis físicos, químicos y mineralógicos. Las áreas de este estudio están compuestas por un viñedo comercial manejado durante 4, 9 y 16 años con el cultivar Pinot noir (Vitis Vinifera), injertado en 1103 Paulsen, y un área bajo campo nativo, ubicada cerca del viñedo para ser utilizada como referencia. Hubo un cambio en la fertilidad del suelo, en todas las profundidades muestreadas y después de 4 años de siembra. La arcilla predominante en el suelo fue la caolinita $(\mathrm{Ct})$, que contiene mica $(\mathrm{Mc})$, feldespato potásico $(\mathrm{Ft}) \mathrm{y}$ cuarzo $(\mathrm{Qz})$. En general, el viñedo mostró cambios en los atributos químicos del suelo a lo largo de los años, con mayor énfasis en las áreas manejadas durante 9 y 16 años, donde el suelo sufrió una mayor oferta de fertilizantes y materiales correctivos agrícolas. Los resultados obtenidos mostraron que en el viñedo cultivado hace 4 años hubo evidencia de Ilitización, resultado de una intensa fertilización potásica en los primeros años de cultivo, que promovió la nueva formación de Ilitas y minerales arcillosos interatificados.

Palabras clave: La vid; Suelos; Mineralogía.

\section{Introdução}

A viticultura é uma importante atividade agrícola no Estado do Rio Grande do Sul, responsável por mais de 50\% da produção de uva e por $90 \%$ da produção de vinhos e derivados no Brasil (IBGE, 2020). Além das características edafoclimáticas e relevo ideal para o desenvolvimento dos vinhedos, a rápida expansão desta cultura se deve principalmente a colonização italiana no estado, entre os anos de 1875 e 1930 (Farias \& Silva, 2016). Nos últimos anos, novos polos de produção têm sido explorados, sobretudo por grandes vinícolas para a produção de uvas finas destinadas a elaboração de vinhos e espumantes. O município de Encruzilhada do Sul apresenta condições de solo e clima apropriadas para o bom desenvolvimento da viticultura. Os solos da região, normalmente Argissolos, entre outras classes, caracterizam-se por uma textura franca a arenosa, com boa drenagem possibilitando o perfeito desenvolvimento radicular da planta, além de fertilidade satisfatória para a cultura, assim, tem demonstrado amplo potencial de aptidão agrícola para o sucesso da viticultura na região (Streck et al.; 2002).

No estudo de Bortoluzi (2012), realizado em áreas de videiras, foi observado aceleração do intemperismo e diminuição do teor de ilita no solo, provocado pela pressão das raízes, acelerando a liberação do K constante na entrecamada deste mineral. Assim como no restante do país, os solos do estado do Rio Grande do Sul são, em sua maioria, naturalmente ácidos (Drescher et al.,1995). Solos ácidos possuem as condições ideais para formação de argilominerais interestratificados, como Vermiculita hidroxi-entrecamada (VHE) e Esmectita hidroxi-entrecamada (EHE), os quais possuem material hidróxi (Al, $\mathrm{K}$, Ca) na entrecamada. Estes polímeros hidróxi modificam significativamente as propriedades físico-químicas dos minerais, diminuindo sua área superficial específica e CTC permanentemente e aumentando sua estabilidade no solo o que confere a este mineral maior resistência ao intemperismo (Melo, 2014).

Tem-se observado que a presença de ácidos orgânicos no solo é capaz de acelerar o intemperismo de minerais primários e de minerais pedogênicos em períodos de tempo relativamente curtos (Castilhos e Meurer, 2001; Chaves, 2014; Korchagin, 2019). Os ácidos orgânicos são derivados da decomposição da matéria orgânica, da exsudação radicular e do metabolismo de microrganismos (Correa et al., 2008). O pH na zona das raízes é modificado, principalmente em função da reação de acidificação, devido ao elevado teor de H+Al. Segundo Marschner (1995), os ácidos orgânicos funcionam como agentes complexantes de metais ligados à fração sólida do solo. A sua quantidade no solo varia conforme a espécie vegetal, conforme observado por George et al., (2002) e Guppy et al. (2005) a concentração de ácidos orgânicos é dois terços menor em áreas cultivadas com lavouras de milho quando comparadas a áreas de florestas, como no caso da Tithonia diversifolia (espécie exótica que constitui algumas florestas no Kenya) que promovem maior eficiência na absorção de $\mathrm{P}$ nas áreas de florestas. Em G. Huang et al. 2020 e H. Ma et al 2020, ainda é possível observar que uma maior quantidade de ácidos orgânicos no solo pode influenciar a atividade enzimática e população bacteriana, aumentando inclusive absorção de metais pesados.

A mudança de áreas de solos de campo nativo para uso com viticultura comercial envolve a correção dessa acidez, normalmente com a adição de calcário, que é o insumo mais utilizado para essa finalidade. Com a aplicação de calcário, ocorre 
a formação de uma frente alcalinizante que avança verticalmente em profundidade no perfil do solo (Amaral et al., 2004). As oxidrilas e os bicarbonatos formados após a calagem são capazes de neutralizar os íons $\mathrm{H}+$ através do fenômeno de troca catiônica. Além da neutralização da acidez, o calcário ainda é fonte dos nutrientes $\mathrm{Ca} 2+\mathrm{e} \mathrm{Mg} 2+$. Com o aumento do pH do solo, ocorre a diminuição de Al3+ disponível, ou seja, ele pode ser removido da camada dos minerais 2:1HE e ser substituído por outro elemento em maior disponibilidade, como por exemplo, o K (Lindsay, 1979; Azevedo et al., 1996).

O solo é um recurso natural lentamente renovável e que é pouco lembrado em ações publicas e governamentais no Brasil, assim, é preciso que sua utilização e ocupação sejam bem planejadas e conduzidas com responsabilidade. O uso e manejo inadequado dos solos podem acarretar impactos negativos sobre suas propriedades, como seu desgaste químico e desestruturação. A mineralogia do solo ao contrário do que se imaginava, pode ser alterada por ações antrópicas (Fink et al.; 2014; Bertolazi et al., 2018; Korchagin, 2019; Chaves, 2020), servindo como uma medida de avaliação das alterações provocadas. Com este estudo busca-se identificar alterações na mineralogia, física e química do solo provocadas pelo manejo e interação entre o solo e as videiras, em um Argissolo Vermelho Distrófico típico após 15 anos de cultivo e utilizando-se um solo com campo nativo como referência.

\section{Metodologia}

\subsection{Situação e localização da área}

O estudo foi realizado em um vinhedo localizado no município de Encruzilhada do Sul, representado na Figura 1, região geomorfológica do Escudo Sul-rio-grandense, à 30³2'38" de latitude sul e 52³1'19" longitude oeste de Greenwich e altitude variando de $200 \mathrm{~m}$ a $400 \mathrm{~m}$ e com relevo formado predominantemente por colinas suaves. O clima na região é classificado como subtropical úmido com períodos de seca no verão (ST UM v) (Maluf, 2000), com temperatura e precipitação média anual de $17,1^{\circ} \mathrm{C}$ e $1.541 \mathrm{~mm}$, respectivamente. O solo da propriedade foi classificado como Argissolo Vermelho Distrófico típico (Santos et al. 2018), formado a partir de granitos, com baixos teores de matéria orgânica e boa drenagem.

O manejo do solo é realizado desde a fase de pré-plantio à manutenção do pomar. A correção da acidez do solo é realizada com a utilização de calcário dolomítico, com média de 10 a 12 t ha-1 por aplicação. São realizadas de 2 a 3 aplicações desta dosagem em pré-plantio e incorporação, visando manter o pH a 6,5, recomendável para as videiras (Comissão, 2016), com aplicação anual seguida de incorporação. Após o plantio as aplicações de calcário peletizado são realizadas a lanço.

A adubação com N, P e K ocorre nas linhas de plantas, a lanço. A adubação nitrogenada foi realizada com aplicação de $61 \mathrm{~kg}$ de $\mathrm{N} \mathrm{ha}^{-1}$, que ocorreu aos 10, 40 e 70 dias após a brotação, enquanto a adubação fosfatada foi realizada com a aplicação de $63 \mathrm{~kg}$ de $\mathrm{P}_{2} \mathrm{O}_{5}$ ha $^{-1}$ e a potássica foi realizada com aplicação de $63 \mathrm{~kg}$ de $\mathrm{K}_{2} \mathrm{O}_{\text {ha }}^{-1}$, aplicados 10 dias antes da poda de inverno e 10 após a brotação dos ramos, de acordo com recomendação de adubação para a cultura (Comissão, 2016).

O Ca e Mg, Mn, Cu, Zn, S e B foram aplicados ao solo juntamente com os fertilizantes NPK, sendo que o Ca e B também são aplicados via foliar no estádio de pré-floração. O Zn, Mn e Cu foram aplicados via foliar, com 3 pulverizações e de forma indireta, para tratamento fitossanitário.

\subsection{Amostragem do solo}

Foram abertas trincheiras nas entrelinhas de plantio, para a coleta de amostras deformadas do solo dos horizontes A2 e Bt1, nas profundidades 0-30 e 30-60 cm, respectivamente. As áreas cultivadas de 1 a 3 possuem espaçamento de $2,5 \mathrm{~m}$ entre linha e 1,3 m entre planta e apresentam as seguintes características de uso:

Área 1: 5,76 hectares com 16 anos de plantio com a cultivar com Pinot noir (Vitis vinifera), enxertada em 1103 Paulsen, com um total de 17.850 plantas;

Área 2: 5,13 hectares com 9 anos de plantio com a cultivar com Pinot noir (Vitis vinifera), enxertada em 1103 
Paulsen, com um total de 15.800 plantas;

Área 3: 6,10 hectares com 4 anos de plantio com a cultivar com Pinot noir (Vitis vinifera), enxertada em 1103 Paulsen, com um total de 18.788 plantas;

Área 4: 10 hectares de campo nativo, composto pela vegetação rasteira e herbácea típicos do bioma pampa (MMA, 2010).

A distribuição espacial das áreas supracitadas pode ser observada em detalhes na Figura 1.

Figura 1. Áreas de estudo do vinhedo e localização do vinhedo em Encruzilhada do Sul - RS.

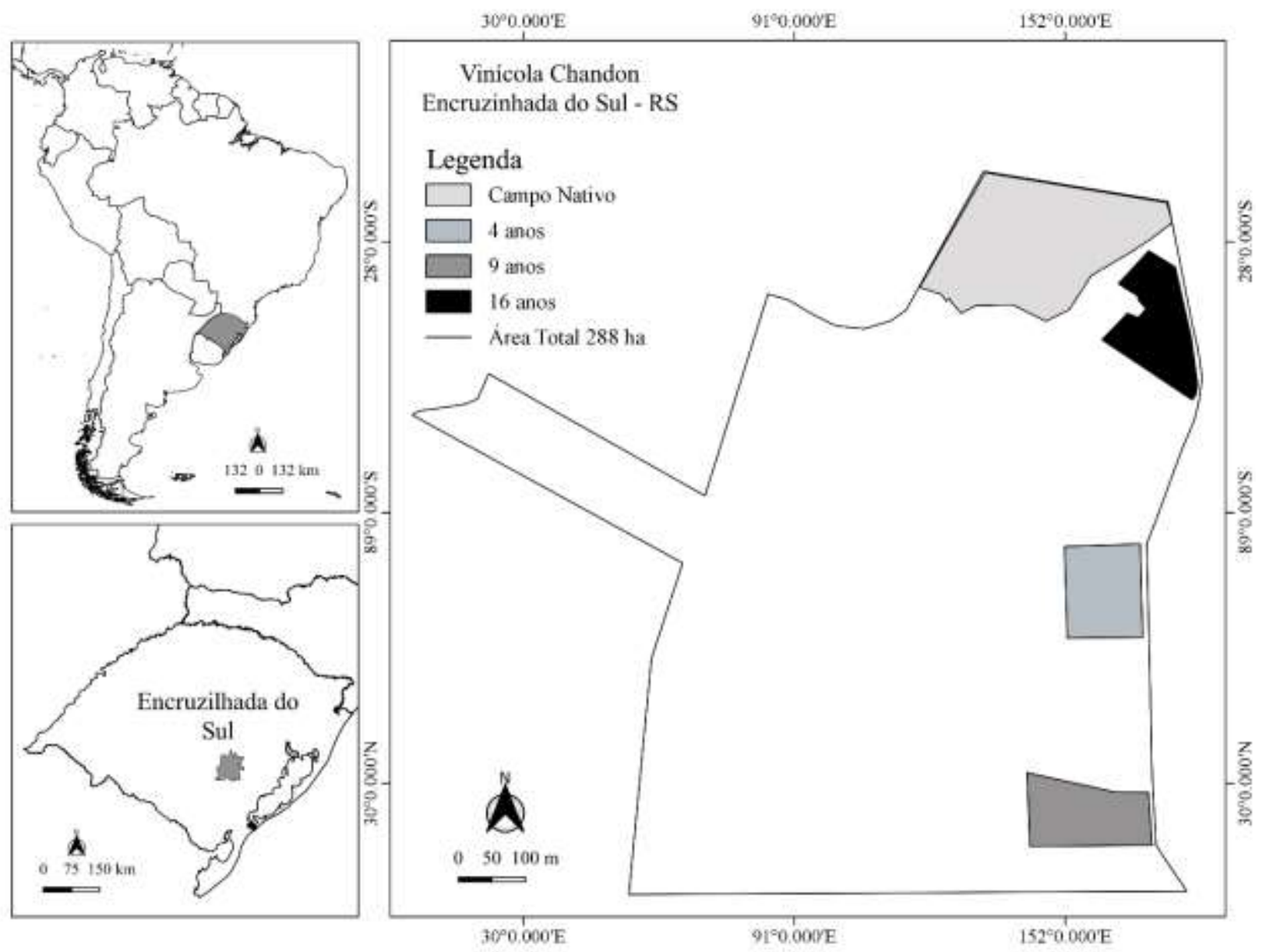

Fonte: Autores.

\subsection{Analises físicas, químicas e mireralógicas do solo}

A textura do solo foi determinada pelo método da pipeta (EMBRAPA 2017), com agitação mecânica de $50 \mathrm{~g}$ de terra fina seca ao ar (TFSA) em solução dispersante $\mathrm{NaOH} 1 \mathrm{~mol} \mathrm{~L}^{-1}$, por 16 horas, em um agitador horizontal tipo shaker a 150 ciclos por minuto (Unterline, 2011). O teor de areia total (AT, em $\mathrm{g} \mathrm{kg}^{-1}$ ) foi quantificado por peneiramento da suspensão em peneira de malha de $0,053 \mathrm{~mm}$, sendo posteriormente diferenciada nas classes areia grossa (AG) $(2,00>\Theta>0,25 \mathrm{~mm})$ e areia fina (AF) $(0,25>\theta>0,05 \mathrm{~mm})$.

O sobrenadante foi transferido para proveta de $1 \mathrm{~L}$, completado o volume com água destilada e após 4 horas realizadas a pipetagem da fração argila total do solo (ARGT, em g kg-1) que foi separada em argila fina (ARGF) $(\Theta<0,2 \mu \mathrm{m})$ e argila grossa (ARGG) $(2,00>\Theta>0,2 \mu \mathrm{m})$, por centrifugação a $2.500 \mathrm{rpm}$ durante $30 \mathrm{~min}$, para a quantificação da argila fina em relação ao material total (Jackson, 1956). O teor de silte $\left(\mathrm{g} \mathrm{kg}^{-1}\right)$ foi determinado por diferença entre o teor de argila e areia e a 
TFSA. O teor de argila dispersa em água (ADA\%) foi realizado com a agitação de $20 \mathrm{~g}$ de TFSA que foram agitadas por 16 horas, com o mesmo procedimento utilizado para a análise das frações finas do solo, porém sem a utilização de dispersante químico.

Os atributos químicos do solo foram determinados de acordo com metodologias descritas por Tedesco et al. (1995). A acidez ativa do solo foi determinada em água $\left(\mathrm{pH}_{\mathrm{H} 2 \mathrm{O}}\right)$ e a acidez potencial do solo $(\mathrm{H}+\mathrm{Al})$, por titulação, após extração com solução de acetato de cálcio $0,5 \mathrm{~mol} \mathrm{~L}^{-1}$; o teor de carbono orgânico do solo (C.O.) foi determinado pela metodologia da combustão úmida Walkley-Black modificado.

O fósforo $\left(\mathrm{H}_{2} \mathrm{PO}_{4}^{-}\right)$e potássio $\left(\mathrm{K}^{+}\right)$disponíveis foram determinados por meio da extração com Mehlich-1; os teores de cálcio $\left(\mathrm{Ca}^{+2}\right)$, magnésio $\left(\mathrm{Mg}^{+2}\right)$ e alumínio $\left(\mathrm{Al}^{+3}\right)$ trocáveis foram determinados por meio da extração com cloreto de potássio ( $\mathrm{KCl}$ a $\left.0,1 \mathrm{~mol} \mathrm{~L}^{-1}\right)$; o manganês $(\mathrm{Mn})$, cobre $\left(\mathrm{Cu}^{+2}\right)$ e zinco $\left(\mathrm{Zn}^{+2}\right)$ foram obtidos com base na extração com $\mathrm{HCl} 0,1 \mathrm{~mol} \mathrm{~L}^{-1} \mathrm{e}$ leitura em espectrofotômetro de absorção atômica; o boro (B) foi obtido por meio da extração com água quente e determinação por calorimetria. A capacidade de troca catiônica do solo (CTC) foi determinada com base na soma dos cátions trocáveis do solo $\left(\mathrm{Na}^{+}, \mathrm{K}^{+}, \mathrm{Ca}^{2+}, \mathrm{Mg}^{2+}\right)$ deslocados por íons de amônia a pH tamponada em 7,0.

A mineralogia do solo foi avaliada na fração argila. Para isso foi realizada a dispersão da TFSA com NaOH $1 \mathrm{~mol} \mathrm{~L}^{-1}$. Após coleta da argila foi realizada a floculação da suspensão com $\mathrm{HCl} 0,1 \mathrm{~mol} \mathrm{~L}^{-1}$, lavagem com solução álcool na proporção 1:1, secagem em estufa a $60^{\circ} \mathrm{C}$ e pulverização em grau de ágata (EMBRAPA, 2011). As análises mineralógicas foram realizadas no Laboratório de Mineralogia do departamento de Solos da UFRGS, as leituras foram realizadas em aparelho Bruker D2 Phaser (Tubo de Cu com filtro de Ni). As amostras de argila foram desferrificadas pelo método ditionito-citratobicarbonato (DCB) (Mehra e Jackson, 1960). Após, as amostras foram lavadas com água destilada seguidas por centrifugação para remover o excesso de sais. Foram confeccionadas lâminas orientadas pelo do método da pipeta (Resende et al, 2005). Os resultados foram interpretados baseando-se nas tabelas de espaçamento basal das reflexões de minerais encontradas em Brindley e Brown (1980).

Conforme Pereira A.S. et al. (2018), esta pesquisa é de natureza quali-quantitativa, tendo em vista as metodologias utilizadas para coleta e consolidação dos resultados apresentados a seguir.

\section{Resultados e Discussão}

\subsection{Atributos físicos do solo}

Pode-se observar que os solos dos locais de coleta apresentam incremento no teor de argila em profundidade, característica diagnóstica dos Argissolos (Tabela 1). No horizonte A os teores de argila variam de 21 a 27\%, enquanto nos horizontes $\mathrm{Bt}$ os teores variam de 32 a $60 \%$ e isso se deve a heterogeneidade natural desses solos, para todas as áreas, com os menores valores observados na área com 16 anos de uso e manejo do solo, sob vinhedo. 
Tabela 1. Atributos físicos das áreas de estudo.

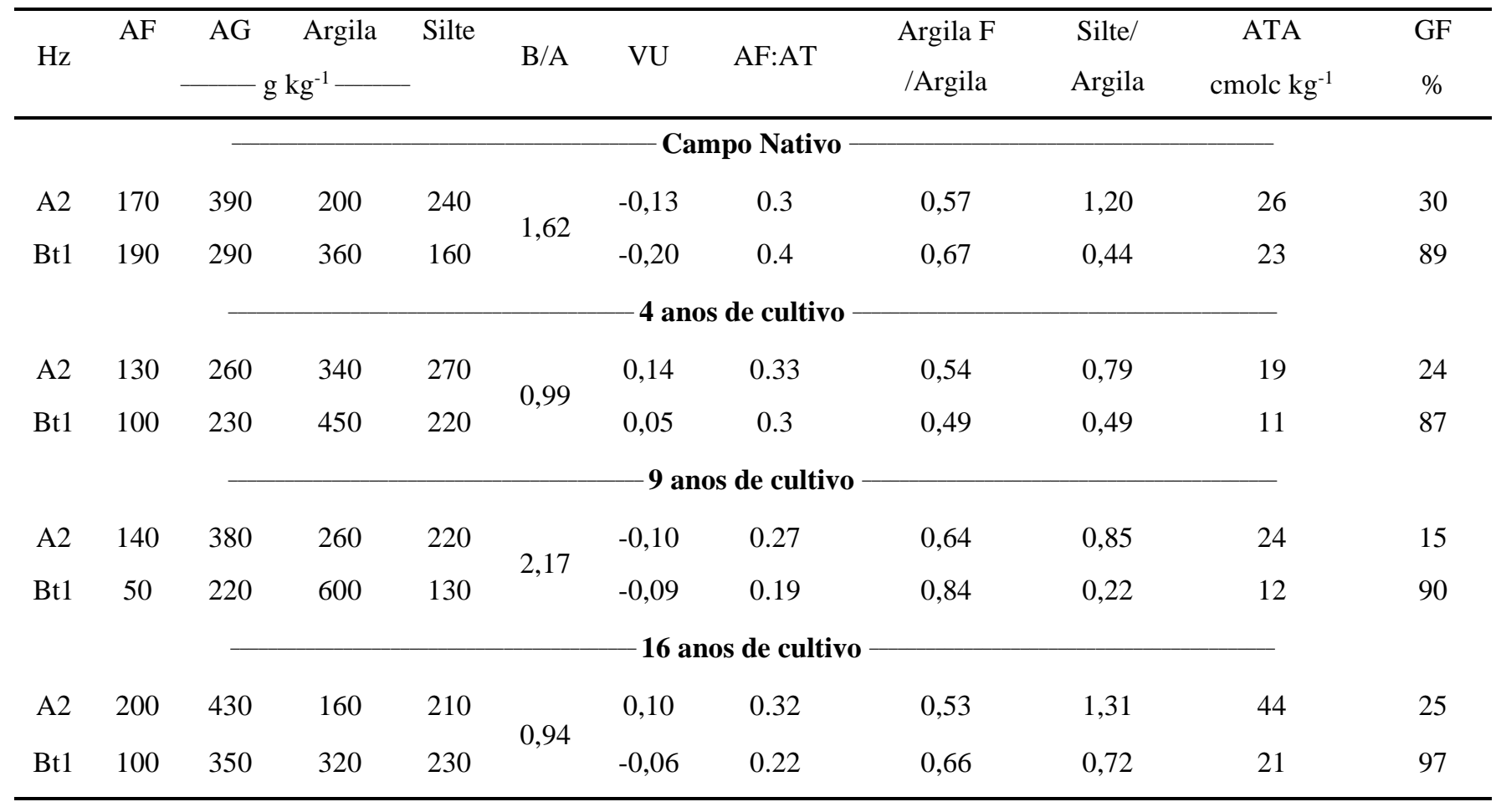

Nota: Hoz = horizonte A2: 0-30 cm e Hoz = horizonte Bt1: 30-60 cm. AT: areia total; AG: Areia Grossa; AF: Areia Fina; 6GF: Grau de Floculação; VU: Valor de Uniformidade; CO: Carbono Orgânico; Ds: Densidade do Solo; Ma: Macroporosidade do solo; Mi: Microporosidade do solo; Pt: Porosidade Total do Solo. Fonte: Autores.

Esse resultado está de acordo com os encontrados por Y. Xu, et al. (2020) que observaram uma diminuição nos teores de argila em solos cultivados por até 15 anos com Eucalyptus spp, esse resultado sugere um ambiente intempérico mais agressivo próximo a rizosfera das plantas de Eucalipto, com uma dissolução dos argilominerais.

\subsection{Atributos químicos do solo}

Devido ao intenso manejo do vinhedo, ocorre uma alteração nos atributos químicos do solo que pode ser observado na Tabela 2. De modo geral, ocorreu um aumento nos valores de $\mathrm{pH}$ do solo do vinhedo, mais evidenciado no horizonte A2 da área com 4 anos de manejo, o que pode ser atribuído às práticas de calagem, o que também diminuiu os teores de alumino trocáveis e aumentou os teores de $\mathrm{Ca}$ e $\mathrm{Mg}$. Lopes et al. (1990) ressalta que o acumulo de fertilizantes, sobretudo os amoniacais e a uréia, faz com que o pH das duas áreas mais antigas seja mais baixo, pois o produto de sua transformação no solo pelos microrganismos resulta em $\mathrm{H}^{+}$(Lopes et. al., 1990), aumentando a acidez do solo na área. O manejo do solo ao longo dos anos de cultivo, contribuiu para um incremento na fertilidade do solo, com acumulo de macro e micronutrientes na camada superficial do solo, devido às aplicações de fertilizantes e ciclagem de nutrientes. 
Tabela 2. Atributos químicos das áreas de estudo.

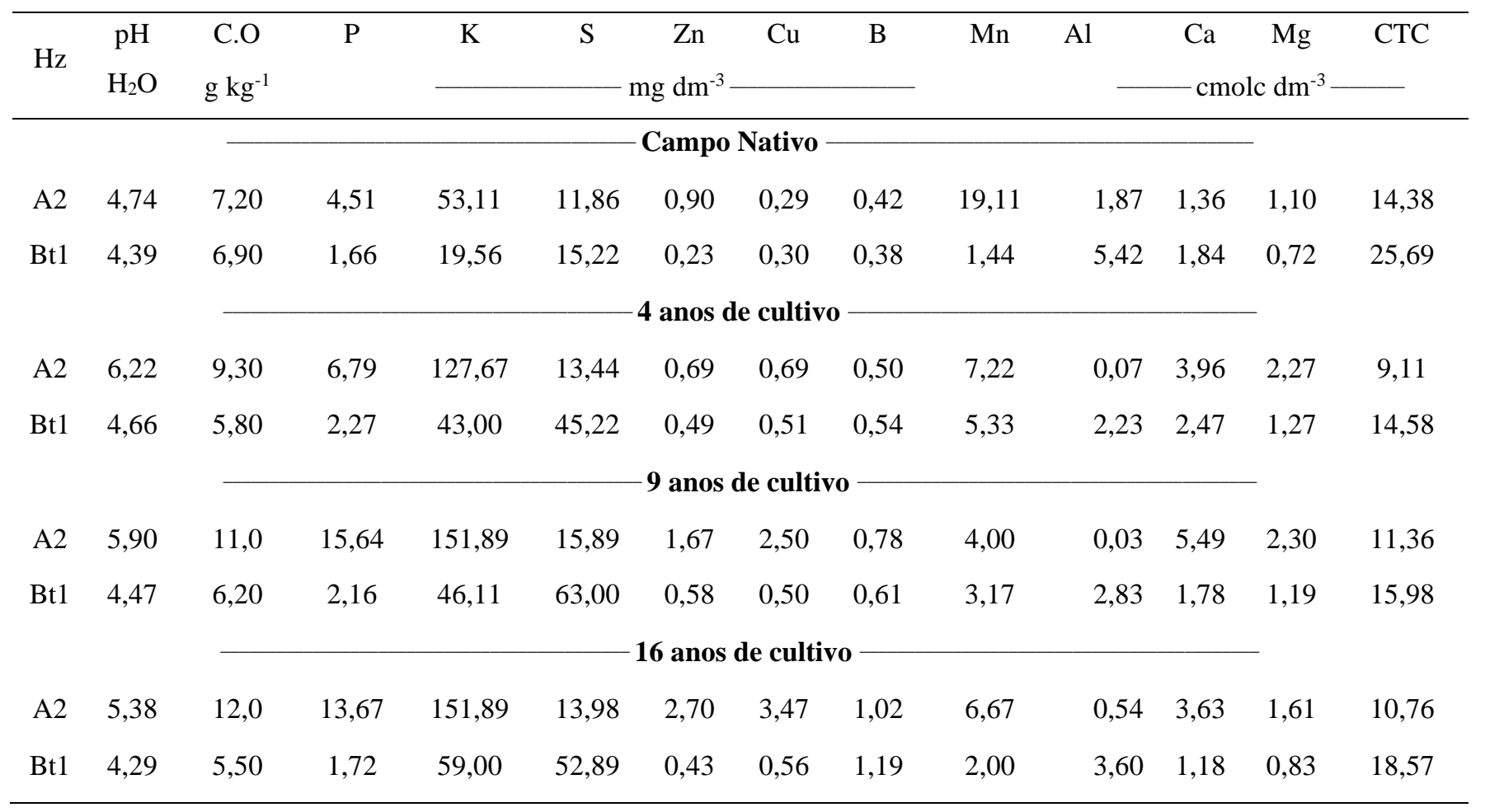

Nota: Hoz = horizonte A2: 0-30 cm e Hoz = horizonte Bt1: 30-60 cm. SB: soma das bases; CTC: capacidade de troca de cátions (média: 5,1-15,0 cmolc kg-1; baixa: $\leq 5,0$ cmolc kg-1); ATA: atividade da fração argila (alta: $\geq 27$ cmolc kg-1, baixa: 27 cmolc kg-1);m: saturação por alumínio; PST: porcentagem de sódio trocável (não sódico 7\%; ligeiramente sódico 7\% - 10\%; Mediamente sódicos 11\% - 20\%; Fortemente sódicos 21\% - 30\%; Excessivamente sódicos > $30 \%$ ); V: saturação por bases (eutrófico: $\geq 50$; distrófico: 50 ). Fonte: Autores.

O teor de C.O. do solo também é maior em superfície, nas áreas com 4, 9 a 16 anos de cultivo, devido aos restos culturais e maior quantidade de produção de massa verde pelas videiras. Reinert et al. (2006) afirmam que o preparo e manejo do solo favorecem as trocas gasosas, criando um ambiente oxidativo que, associado à redução da proteção física de fragmentos de matéria orgânica dentro de agregados, resulta em rápido declínio do teor matéria orgânica, este efeito é mais observado nos horizontes $\mathrm{Bt}$, onde houve decréscimo do teor de C.O. quando comparado ao campo nativo.

\subsection{Atributos mineralógicos do solo}

Na Figura 2 está representado o difratograma das amostras de argila de cada área estudada, devido o material ser de origem granítico, podemos verificar reflexos referente à Mica $(\mathrm{Mc}) / \mathrm{Ilita}(10 \mathrm{~nm})$ e ao Feldspato potássico $(\mathrm{Ft})$. $\mathrm{O}$ pico mais intenso é o da caulinita $(\mathrm{Ct})(7,1 \mathrm{~nm})$, característico de Argissolos cauliníticos, os quais possuem grande ocorrência no estado do Rio Grande do Sul. Ainda podemos observar um reflexo de quartzo (Qz). Com exceção do pico da mica/ilita, os outros reflexos são semelhantes em todos as áreas estudadas. 
Figura 2. Difratogramas de raios- $X$ da fração argila $<2 \mu$ dos horizontes A2 e Bt1.

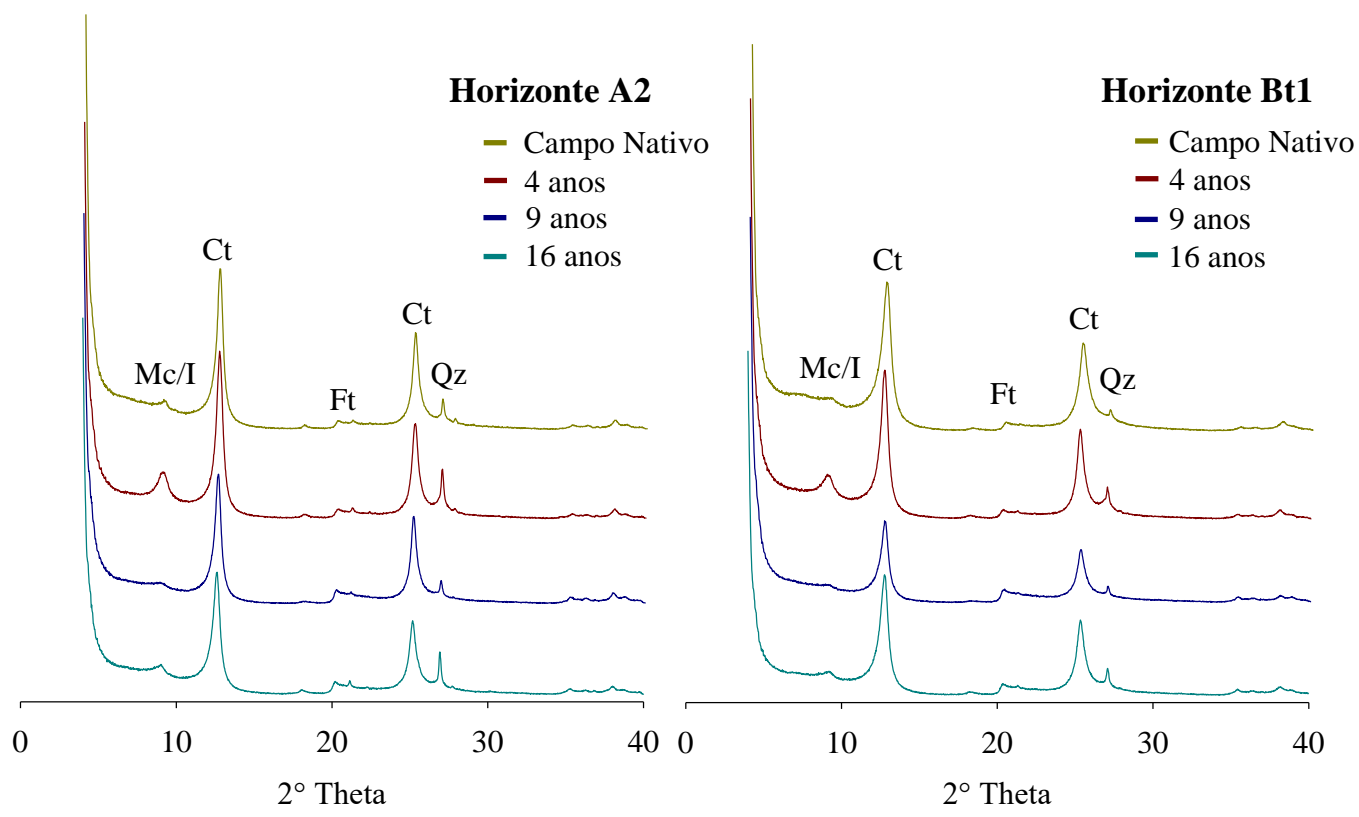

Nota: Mc: mica; Ct: caulinita; Qz: quartzo; Ft: feldspato potássico; I: Ilita. Fonte: Autores.

No solo mais recentemente cultivado (4 anos de plantio) observou-se um pico mais intenso na região de $1 \mathrm{~nm}$ (região de ocorrência das micas) o que indica o predomínio deste mineral. Podemos observar um efeito de ilitização (16 anos de cultivo) nos solos onde houve aplicação de calcário e adubação potássica (Bortoluzzi et al., 2005). A formação da Ilita faz-se possível na presença de minerais 2:1 ou interestratificados que são capazes de adsorver especificamente o K que está em grande disponibilidade na solução do solo.

$\mathrm{O} \mathrm{CaCO}_{3}$ fornecido pela calagem, pode promover a despolimerização dos minerais 2:1 HE (extração do Alumínio da entrecamada) e há posterior ocupação da entrecamada com K, provocando o pico em 9,96 nm. Nos anos subsequentes, podemos observar em 9 e 16 anos a diminuição do pico da mica em virtude da formação da ilita na estrutura que antes era uma mica ou um mineral 2:1. O solo é, portanto, capaz de portar-se tanto como fonte, tanto como dreno de nutrientes. A Ilita é um tipo de mica pedogênica com alto grau de alteração, ocorre predominantemente na fração argila. Em condições específicas o K pode ser absorvido especificamente neste processo denominado Ilitização (Melo, 2014). Este processo depende do tipo de mineral presente no solo, da concentração de $\mathrm{K}$ na solução e de ciclos de umedecimento e secagem que podem ter sido evidenciados pela camada argilosa no horizonte Bt1 (Bortoluzzi, 2012).

\section{Conclusão}

Verificou-se alterações, em superfície, dos atributos químicos do solo, influenciada pela adubação e correção do solo ao longo dos anos de manejo do pomar. Essas alterações são mais destacadas nas áreas manejadas por 9 e 16 anos, que além do efeito do acumulo pode ser atribuída à influência do teor de argila que são maiores nessas áreas. O solo em estudo apresenta grande quantidade de minerais primários e secundários, fonte de K. Os resultados obtidos demonstraram que houve uma evolução diferenciada na mineralogia, devido à adubação K, indicando a neoformação de Ilitas e interestratificados nas áreas manejadas por 4 e 16 anos quando em comparação ao campo nativo.

Como sugestão para futuros estudos, aconselharia como sequência a este estudo mineralógico, que fosse realizado também nas frações silte e areia, para verificar se nessas frações o estudo da mineralogia também permite evidenciar alterações. Assim como, o fracionamento da argila $\Theta<2 \mu$ desferrificada em diferentes tamanhos de argila (fina, média, grossa) 
pode auxiliar no entendimento das dissoluções e neoformações ocorridas nesta fração.

\section{Agradecimentos}

Aos colegas e servidores da Universidade Federal do Rio Grande do Sul pelas contribuições para com este estudo e aos órgãos de fomento CAPES e CNPq pelo auxílio financeiro.

\section{Referências}

Amaral, A. S., Anghinoni, I., Hinrichs, R., \& Bertol, I. (2004). Movimentação de partículas de calcário no perfil de um Cambissolo em plantio direto. Revista Brasileira de Ciência do Solo, 28(2), 359-367. https://doi.org/10.1590/S0100-06832004000200014.

Azevedo, A. C., Kampf, N., \& Bohnen, H. (1996). Alterações na dinâmica evolutiva de Latossolo Bruno pela calagem. Revista Brasileira de Ciência do Solo, v 20:191-198.

Bortoluzzi, E.C., Moterle, D.F., Rheinheimer, D.S., Casali, C., Melo, G.W., \& Brunetto, G. (2012). Mineralogical changes caused by grape production in a regosol from subtropical Brazilian climate. Journal of Soils and Sediments, 854-862. https://doi.org/10.1007/s11368-012-0509-x

Bortoluzzi, E. C., Santos, D. R. dos, Kaminski, J., Gatiboni, L. C., \& Tessier, D. (2005). Alterações na mineralogia de um Argissolo do Rio Grande do Sul submetido à fertilização potássica. Revista Brasileira de Ciência do Solo. 29(3), 327-335. https://doi.org/10.1590/S0100-06832005000300002

Comissão de Química e Fertilidade do Solo (2016). Manual de adubação e calagem para os Estados do Rio Grande do Sul e de Santa Catarina. Sociedade Brasileira de Ciência do Solo. 10 eds. Porto Alegre, 400p.

Corrêa, M. M., Andrade, F. V. de, Mendonça, E. S., Schaefer, C. Ernesto G.R., Pereira, T. T. C., \& Almeida, C. C. (2008). Ácidos orgânicos de baixo peso molecular e ácidos húmicos e alterações em algumas propriedades físicas e químicas de Latossolos, Plintossolo e Neossolo Quartzarênico. Revista Brasileira de Ciência do Solo, 32(1), 121-131. https://dx.doi.org/10.1590/S0100-06832008000100012

Drescher, M.., Bissani, C.A.., Giasson, E. et al. (1995) Avaliação da fertilidade dos solos do Estado do Rio Grande do Sul e necessidade de adubos e corretivos. Porto Alegre: Depto de Solos da UFRGS, 24p. (Boletim Técnico, 7).

Embrapa - Empresa Brasileira de Pesquisa Agropecuária. Centro Nacional de Pesquisas de Solos. (2011). Manual de métodos de análises de solos. 2.ed. Rio de Janeiro: Embrapa Solos, 230p.

Ernani, P. R., Ribeiro, M. F. S. \& Bayer, C. (2004). Chemical modifications caused by liming below the limed layer in a predominantly variable charge acid soil. Communications in Soil Science and Plant Analysis. 35(5), 889-901. https://dx.doi.org/10.1081/CSS-120030365

Guoyong Huang A.B.., Jinwei You, A.., Xiupei Zhou, A.., Chao Ren, A.., Md Shoffikul Iislam, A., C. \& Hongqing Hu, A. (2020). Effects of low molecular weight organic acids on $\mathrm{Cu}$ accumulation by castor bean and soil enzyme activities. Ecotoxicology and Environmental Safety. 203 -110983. https://doi.org/10.1016/j.ecoenv.2020.110983

Hang, M.., Xuedan, L.., Mingyang, W.., Guoquan, Z.., Siyu, H.., Dan, L. \& Heng, X. (2020). Elucidation of the mechanisms into effects of organic acids on soil fertility, cadmium speciation and ecotoxicity in contaminated soil. Chemosphere 239-124706. https://dx.doi.org/10.1016/j.chemosphere.2019.124706

Jayarama., Shankar, B.N., Violet, M.D.S. (1998). Citric acid as a potential phosphate solubiliser in coffee soils. Indian Coffee, p.13-15

Kochargin, J.., Bortoluzzi E. C.., Moterle, D. F. \& Petry, C. (2019). Evidences of soil geochemistry and mineralogy changes caused by eucalyptus rhizosphere. Catena. 175(12), 132-143. https://dx.doi.org/10.1016/j.catena.2018.12.001

Lindsay, W. L. (1979). Chemical equilibria in soils. John Wiley \& Sons. 449.

Luciano, R. V. (2012). Variabilidade espacial e temporal de atributos do solo e sua relação com a composição da uva para vinificação no Planalto Catarinense. 147p. Tese (Doutorado) - Universidade do Estado de Santa Catarina, Lages.

Maluf, J. R. T. (2000). Nova classificação climática do Estado do Rio Grande do Sul. Revista Brasileira de Agrometeorologia, 8(1), 141-150.

Melo, V. F., Novais, R. F., Fontes, M. P. F., \& Schaefer, C. E. G. R. (2000). Potássio e magnésio em minerais das frações areia e silte de diferentes solos. Revista Brasileira de Ciência do Solo, 24(2), 269-284. https://doi.org/10.1590/S0100-06832000000200004.

Melo, V. F., Novais, R. F., Schaefer, C. E. G. R., Fontes, M. P. F., Singh, B. (2002). Mineralogia das frações areia, silte e argila de sedimentos do Grupo Barreiras no município de Aracruz, Estado do Espírito Santo. Revista Brasileira de Ciência do Solo, 26(1),22-35. https://doi.org/10.1590/S010006832002000100004

Pereira A. S.., Shitsuka, D. M.: Parreira, F. J., Shitsuka, R. (2018). Metodologia da pesquisa científica. UFSM.

Reinert, D. J.., Reichert, J. M. (2006). Propriedades físicas do solo. Universidade Federal de Santa Maria. 18p.

Resende, M.., Curi, N.., Ker., J. C.., Rezende, S. B. de. (2005). Mineralogia de Solos Brasileiros - Interpretações e Aplicações. Editora UFLA. 201 p.

Rheinheimer, D. S., Santos, E. J. S., Kaminski, J., Bortoluzzi, E. C., \& Gatiboni, L. C. (2000). Alterações de atributos do solo pela calagem superficial e incorporada a partir de pastagem natural. Revista Brasileira de Ciência do Solo, 24(4), 797-805. https://dx.doi.org/10.1590/S0100-06832000000400012. 
Research, Society and Development, v. 10, n. 2, e24610212563, 2021

(CC BY 4.0) | ISSN 2525-3409 | DOI: http://dx.doi.org/10.33448/rsd-v10i2.12563

Santos, H. G. et al. (2018). Sistema brasileiro de classificação de solos. (5a ed.), Brasília, DF: Embrapa. 356 p.

Streck, E. V.., Kämpf, N. \& Dalmolin, R. S. D. (2002). Solos do Rio Grande do Sul. Porto Alegre: Emater/RS - UFRGS, 126 p.

Tedesco, M. J., Gianello, C., Bissani, C. A., Bohnen, H. \& Wolkweiss, S. J. (1995). Análises de solo, plantas e outros materiais. (2a ed.), Universidade Federal do Rio Grande do Sul, 174p. (Boletim Técnico, 5)

Yuxing Xua, B., Apeng, D., Zhichao, W., Wankuan, Z., Chao, L., \& Lichao, W. (2020). Effects of different rotation periods of Eucalyptus plantations on soil physiochemical properties, enzyme activities, microbial biomass and microbial community structure and diversity. Forest Ecology and Management. 456117683. https://doi.org/10.1016/j.foreco. 2019.117683 